\title{
Visualization in models of transformation of social space of the Eurasian macroregion: the example of the Urals
}

\author{
Sergey Gordeev ${ }^{1, *}$, Sergey Zyryanov ${ }^{1}$, Arseniy Sitkovskiy ${ }^{1}$ \\ ${ }^{1}$ Chelyabinsk branch of Russian Presidential Academy of National Economy and Public \\ Administration, Chelyabinsk, Russia
}

\begin{abstract}
The relevance of the topic determines a lot of structural socioeconomic changes associated with both globalization and crisis processes. Such changes affect various aspects of spatial development, including the transformation of social space. Prospects for research into the transformation of social space in such conditions are largely related to the development of complex problem-adapted systems of models and the use of computer technologies - visualization tools. These models consider the interconnected spatial objects most significant for transformation. Such objects include zones of transport corridors and agglomeration processes. The purpose of the research results presented in the article is to determine and approbate a number of provisions, the spatial development of the macroregion, as a complex heterogeneous multilevel socio-economic system. The key issues here are the construction of a multilevel framework of social space when adapting local models. In the study, the base was the territory of the macroregion of the "Big Urals". The peculiarities of the methodology, first of all, are related to the issues: determination of the most significant elements of the structure and characteristics of the transformation of social space and building a system of informationadapted models. The following issues are considered here: problemoriented zoning of territories, transformation of the settlement framework, integration of the most significant objects of social transformations. The main results of the research are related to the possibilities of significantly expanding the class of tasks for managing regional and municipal development, solving problems of strategic planning and forming programs for the development of territories.
\end{abstract}

\section{Introduction}

Significant structural changes in the economy and the transformation of social space are increasing as global structural changes in the economy and crisis processes manifest themselves. In such conditions of significant changes, the assessment of the prospects for transformation of the most dynamic spatial objects (associated with high economic growth and the development of communications) acquires particular importance. It is these objects

*Corresponding author: sgordeev222@gmail.com 
that become a kind of "driver" of regional transformations. They largely change the trajectory of development of the surrounding territories. The influence of such spatial objects of significant socio-economic transformations often goes beyond the historically established administrative boundaries of territories. In such cases, it is inevitable to consider the prospects for spatial development at the level of macroregions. Social space, from the point of view of management, can be considered as the distribution of various types of capital in a certain territory (economic, political, social, cultural, academic, human). In general, the social space is considered as a heterogeneous set of interconnected vector objects.

New directions of research of complex, heterogeneous and often specific socioeconomic systems of macroregions are largely associated with the possibilities of wider application of computer technologies. In studies of spatial development, a special place is occupied by the use of problem-adapted computer graphics technologies - visualization.

Further, the article discusses the issues of research into the transformation of the social space of the macroregion. Among them, updating both the fundamentals of the strategic planning methodology and the tools for finding solutions. Specific features, socio-economic differences and heterogeneity of many territories predetermine the need to analyze the development of a macro-region as a complex, heterogeneous, multi-level and largely unique socio-economic system.

\section{Materials and Methods}

In studies of the spatial socio-economic development of a macroregion, two groups of factors are touched upon. On the one hand, the factors of prolongation of the trajectory of the inherited spatial development. Among them, well-known and relatively stable factors characterizing traditional competitive advantages and determining the trajectory of the previous development of the territory (geographic specificity, social conditions, etc.). On the other hand, less studied factors of transformation of spatial development are considered. Among them: the development of communications and the formation of transport corridors, agglomeration processes, the formation of agglomerations.

In this case, the general subjective framework of the national economy is considered as a set of socio-economic entities, taking into account their interrelationships (state, regions, industries, enterprises and organizations, households, individuals). Geographically, the same elements form the spatial structure of social space. The complex and heterogeneous spatial organization of social space is one of the keys and at the same time local factors that determine the individuality, the specifics of building models of spatial development.

Transformations of the settlement framework in the context of many socio-economic changes are primarily reflected in the deepening of the territorial concentration of the population. The complexity of the settlement framework: the presence and location of heterogeneous "centers of gravity", the multiplicity of the "cores" of urban settlements, differences in dynamics and its polarization by types of settlements, predetermine the multilayer structure of the settlement framework in models of spatial development. First of all, the specificity is reflected in the settlement framework of the territory.

The rapidly changing, dynamic objects of the settlement framework have the greatest impact on the transformation of social space. Changes in the settlement framework as a backbone settlement network, supplemented by a multitude of digital assessments, largely characterize the regional vector of further development and, as a first approximation, reflect the transformation of social space.

The structure of the Eurasian settlement framework is determined by the fundamental properties of the geographic space with an uneven distribution of the population. This structure is characterized by a high concentration in certain densely populated areas, as well 
as vast territories with a minimum of permanent population. Such an uneven concentration of the population and the "contrast" of the settlement framework is reflected in the specificity of the transformation of the social space of the Ural macroregion. Further, this circumstance predetermines the main general characteristics of the models under consideration.

The main issues in the construction of models for the transformation of the settlement framework are largely related to the search for a combination of components - the integration of local models that characterize various socio-economic processes. Further, these and others, including interdisciplinary issues, are considered at several levels of detail. As a result, a complex multi-level system of models for the transformation of spatial socio-economic systems is formed. In such a system of models, when analyzing the transformation of the settlement framework, the inherited patterns of previous dynamics and trends of prospective development are considered.

The choice of a combination of various models, depending on the issues under study, is inevitably associated with the issues of adaptation of previously approved methodological foundations to new specific territorial conditions. In general, the adaptation of a universal conceptual model to reflect regional specificity involves the imposition of a symmetric ordered hierarchical model on a complex heterogeneous network structure of the spatial settlement framework (for example, within the framework of the concept of systemic stability of the regional economy [1,2]). The settlement framework in this case integrates the main objects of social space [3].

Determination of the structure of the settlement framework for the integration of the most significant objects for transformation of social space in the form of problem-oriented schemes for the development of territories is a key point in the methodology for finding solutions using spatial information-adapted models. Preparation of such schemes in the format of cartogram makes them look like a classical map ("geographical scheme" or a geographical image "similar to a map"). Similar cartogram (sometimes "figurativegeographical maps") are an abstract geometric image of geographic space and individual objects. They can be considered as special graphic models that allow you to highlight the properties of real spatial systems, including the elements of the structural frame and their basic properties. Among the models capable of displaying a territorial object at different levels of abstraction and formalization, chart maps take their definite, intermediate place and become the basis for the preparation of more detailed models. In fact, they are drawings, where spatial objects are depicted according to certain rules that differ from a number of requirements of cartography [4]. Their preparation is associated with the classifications of spatial objects and the adaptation of geoinformation technologies [5].

Other significant changes in the presented update of the methodology for analyzing spatial development and transformation of social space are associated with the use of information-adaptable models (within the framework of the "soft systems" methodology the application of systems thinking to non-systematic situations [6]). An example of the use of visualization technologies is presented below in the results of studies on the formation of models for the transformation of spatial development.

The analysis of changes in the settlement framework is complicated by the contrast of its structure and the variety of spatial objects in conditions of a lack of information. In the study under consideration, at the initial level of analysis (detailing), the Ural macroregion was considered in the format of agglomeration zones and transport corridors (the main objects of mutual influence - "attraction" in the regional social space). The zones of the main transport corridors along the main highways uniting agglomerations (zones of agglomeration processes) are of particular importance in the spatial transformation of "contrasting" Eurasian territories. 
The key issues for determining the main parameters of spatial development models are the issues of problem-oriented zoning. The interconnection of various spatial objects makes it possible to structure the social space, based on the step-by-step application of various visualization technologies.

In the general case, the models and systems of zones reflect the specific historical patterns of "inherited development" ("Path Dependence") for the macroregion [7, 8]. Further, against their background, new trends are considered: urbanization [9] (associated with agglomeration processes and the formation of agglomerations), transformation of communications (associated with migration, change in logistics and development of transport corridors $[10,11])$.

Given the diversity of regional specifics, in order to consider spatial transformations, first of all, one should focus on three sets of factors. Among them are the determining factors:

- the most general trends in social and economic dynamics,

- the inertial component of development ("Path Dependence"),

- growth of key elements of spatial transformation (agglomerations, transport corridors, etc.).

An example of using visualization technologies to form transformation models is further presented in the research results.

\section{Results}

Examples of visualization of "drivers" of transformation (the core of the macroregion, agglomerations, transport corridors and "points of growth") for the model of the macroregion were considered for the central part of the territory of the "Great Urals" with the intersection of many transport corridors. This territory includes the main areas of the Ural economic region of Russia and the adjacent transboundary areas of Northern Kazakhstan. A number of important transport corridors intersect here as well.

The development of such a macro-region is largely determined by the "inherited trajectory" (within the framework of the corresponding administrative-territorial division). The regional centers of the regions of Russia located within the macroregion of the Urals, as the most significant settlements, are traditionally considered as promising points of growth and, at the same time, zones of "drivers" that largely determine the transformation of social space. A multilevel scheme of transformation of the settlement framework of the central part of the Ural macroregion (with the allocation of zones of agglomeration processes and differentiation of transport corridors) is shown in Fig. 1.

The presented scheme first characterizes the structure of the social space framework, including the specificity of the spatial concentration of the population, the directions of interregional integration, determined by the mutual arrangement of agglomeration zones and zones of transport corridors. A similar characteristic is given by assessing the distribution of the population in the main cities - the centers of agglomeration processes and the prospective development of the Ural macro-region. This cartogram serves as the basis for assessing subsequent transformations of social space.

In Fig. 1 marked: zones of agglomeration processes within an hour of transport accessibility from the main cities (marked with a dotted line). The size of the designation of agglomeration centers (main cities) is proportional to the number. The size of the lines reflecting transport corridors is determined based on the assessments of their importance (the largest in the main transport corridors of Russia) Separately, the central zone of promising agglomeration interregional relationships is marked - the "core" of the macroregion (the space of the conditional agglomeration "core" due to the proximity of the 
largest agglomerations of Yekaterinburg city and Chelyabinsk city is highlighted by a dotted line).

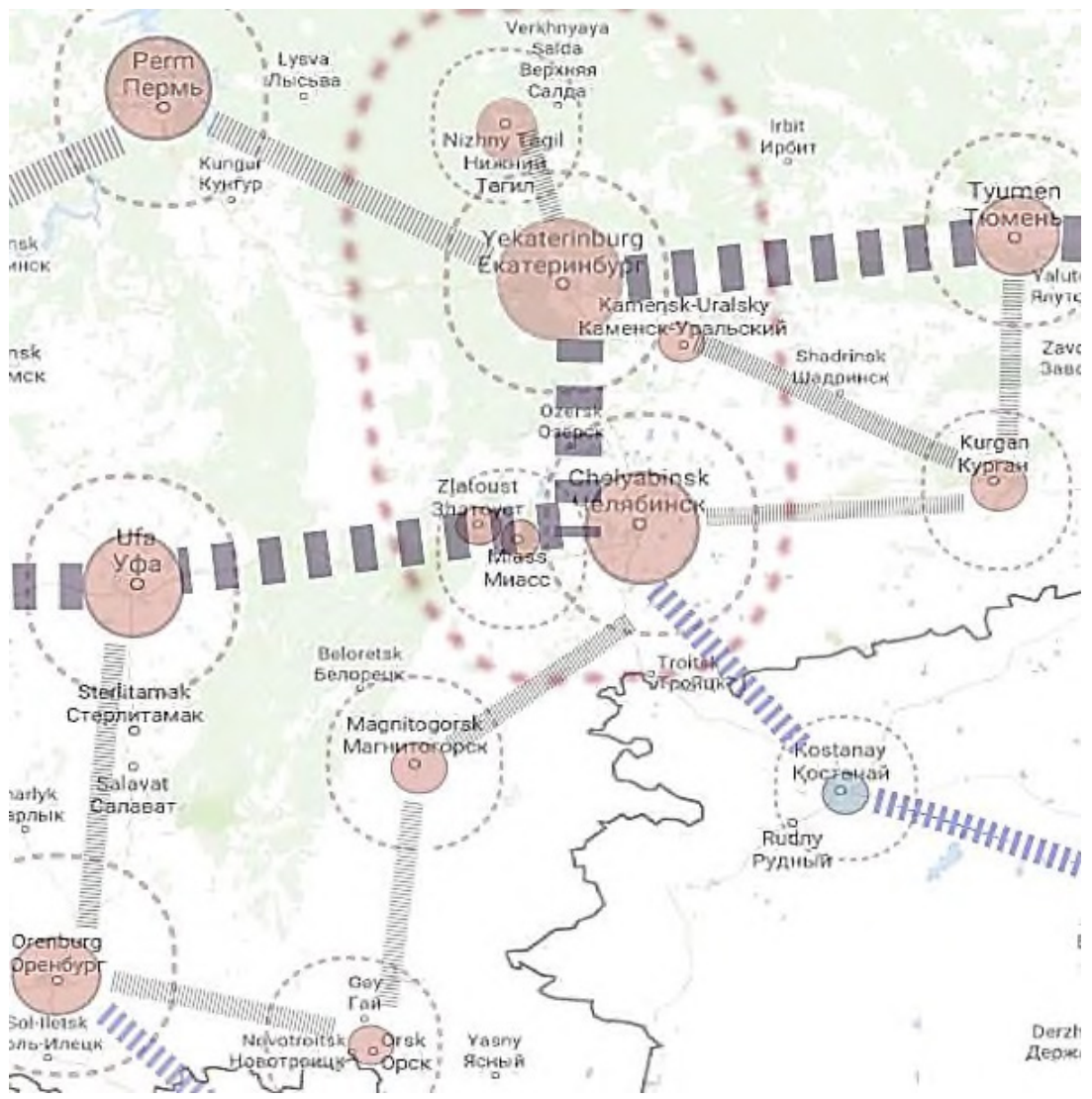

Fig. 1. General scheme of transformation of the settlement framework of the central part of the Ural macroregion, in the format: centers of gravity, zones of agglomeration processes and transport corridors.

The zones of agglomeration processes of the regional centers of the macroregion of the Urals of the largest cities (Perm, Ufa, Yekaterinburg, Chelyabinsk, Tyumen) are within effective daily transport accessibility from each other and other cities (including Kostanay in the adjacent territory of Kazakhstan). Such zoning of the Urals macro-region of the first level of detail allows one to proceed to a more detailed digital analysis of the transformation of social space, taking into account possible interconnections of territories. Such information, complementing the cartogram graphics, provides digital characteristics of the settlement frame and creates a basis for assessing changes in the social space. An example of a diagram of the distribution of the urban population by regional centers and other settlements for the central part of the Ural macroregion is shown in Fig. 2 (according to official statistics for 2018). 


\begin{tabular}{|l|r|r|r|}
\hline $\begin{array}{c}\text { Name of the administrative- } \\
\text { territorial entity }\end{array}$ & $\begin{array}{c}\text { Total population, in } \\
\text { million people }\end{array}$ & $\begin{array}{c}\text { The share of the } \\
\text { administrative center in the } \\
\text { total population, } \%\end{array}$ & $\begin{array}{c}\text { The share of other } \\
\text { urban settlements in } \\
\text { the total population, } \%\end{array}$ \\
\hline Sverdlovsk region & 4,33 & $33 \%$ & $51 \%$ \\
\hline Republic of Bashkortostan & 4,07 & $27 \%$ & $35 \%$ \\
\hline Chelyabinsk region & 3,50 & $34 \%$ & $49 \%$ \\
\hline Perm region & 2,63 & $40 \%$ & $36 \%$ \\
\hline Orenburg region & 1,99 & $28 \%$ & $32 \%$ \\
\hline Tyumen region & 1,43 & $50 \%$ & $14 \%$ \\
\hline Kostanay region & 0,88 & $26 \%$ & \\
\hline Kurgan region & 0,86 & $38 \%$ & $27 \%$ \\
\hline
\end{tabular}

Fig. 2. Distribution of the urban population of the central part of the Ural macroregion by regional centers and other settlements.

\section{Conclusion}

Summarizing the results of the presented studies, the following should be noted. The construction of local information-adapted models of the transformation of social space is largely determined by conceptual provisions, reflected in two basic components. The first component is a scheme that reflects the spatial specifics of the macroregion (with varying degrees of detailing of factors that are difficult to formalize). The second is complementary to the scheme sets of digital characteristics (defining the main parameters and relationships of the objects under consideration). Taken together, they define as a statement of general characteristics of applied problems and individual components of the system of models. The first component largely reflects the spatial competitive advantages of the macroregion, the second creates the preconditions for the assessment system and the construction of digital models.

The creation of information support with a combination of two components (more general graphic and detailed digital) is the starting point for finding solutions to many managerial problems of spatial development. Such problem-oriented information support, in conditions of limited information, largely determines the "contours" - the main characteristics of the system of models. Further, the adaptation of the tools for finding solutions within the framework of the "soft systems" methodology is also touched upon.

Updating the foundations of the methodology for finding solutions using informationadapted "soft" models in the visualization of spatial structures can significantly expand the scope of management tasks of spatial development. An opportunity appears at a qualitatively new level, with coverage of a significantly larger number of factors, to solve a large number of management tasks.

Among such tasks: the search for regional promising areas of development, issues of intermunicipal development, the formation of growth points, the definition of zones of integration and concentration of socio-economic potential. Detailed analysis of spatial development presupposes the subsequent zoning of territories in the "core-periphery" format (within the framework of the already identified problem of territorial differentiation [12]).

As part of the analysis of the departure from the inherited trajectory of previous development (the territorial aspect of "Path dependence"), the main promising areas of research are associated with changes in key trends in regional and municipal development. In detailing, the following questions are raised about the influence of the territorial aspect of "Path dependence", the influence on spatial development:

- Strategies of the largest innovative companies [13]; 
- The existing network of engineering infrastructure: roads, railways, power grids, etc. [14];

- Residual urban development and urban planning [15], etc.

All the presented results further create the prerequisites for considering at a qualitatively new level many problems of strategic planning and the formation of programs for the development of territories, ensuring the effectiveness of management of regional and municipal development.

\section{Acknowledgement}

The authors are grateful to the Russian Foundation for Basic Research for the financial support of the given article. Grant RFBR 19-010-00964 "Modeling and visualization of spatial development scenarios of the transboundary macro-region exemplified by the Urals and Northern Kazakhstan."

\section{References}

1. G.B. Kleiner, The economy of the region 2, 50-52 (2015)

2. G.B. Kleiner, The economy of the region 3, 9-17 (2015)

3. S.S. Gordeev, Scientific Yearbook of the Center for Analysis and Forecasting 1(3), 929 (2019)

4. B. Rodoman, Geographical bulletin 1 http://press.psu.ru/index.php/geogr/article/view/606

5. P. Checkland, Systems Research and Behavioral Science 17 (2000) doi:10.1002/10991743(200011)17

6. S.S. Gordeev, Bulletin of Chelyabinsk state university 11(393), 37-49 (2016)

7. A.A. Auzan, Bulletin of Moskow state university 6(1), 3-17 (2015)

8. S.N. Rastvortseva, Russian journal of economic theory 15(4), 633-642 (2018)

9. J. Laird, James, A.J. Venables, Transport Policy 56, 1-11 (2017)

10. M. Roberts, M. Melecky, T. Bougna, Y. Xu, J. Regional Sci., 1-42 (2019) doi: 10.1111 jors. 12467

11. C.N. Berg, U. Deichmann, Y. Liu, H. Selod, The Journal of Development Studies 53(4), 465-480 (2017)

12. V.I. Barkhatov, D.A. Pletnev, Yu.Sh. Kapkaev, Society and power 5(79), 65-83 (2019) doi:10.22394/1996-0522-2019-5-65-83

13. K. Kotilainen, P. Aalto, J. Valta, A. Rautiainen, M. Kojo, B. Sovacool, Policy Sciences 52, 573-600 (2019) doi:10.1007/s11077-019-09361-3

14. C. Zhan, M. Jong, H. Bruijn, Journal of Urban Technology 24(4), 73-93 (2017) doi:10.1080/10630732.2017.1334862

15. A. Kwamie, H. Dijk, E. Ansah, I. Agyepong, Health Policy and Planning 31(3), 356366 (2016) doi:10.1093/heapol/czv069 